\title{
Interlocuções entre a análise do discurso e os estudos da tradução: algumas contribuições para o ensino de línguas
}

\author{
Fabiele Stockmans de Nardi ${ }^{1}$ \\ Sinara de Oliveira Branco ${ }^{2}$
}

\begin{abstract}
This paper aims to gather specific ideas coming from Translation Studies and Pêcheux's Discourse Analysis to create a discussion regarding the space of the mother tongue and translation in foreign language teaching. The starting point involves both the consideration of translation as a tool to help the learning process of a foreign language and also discourse analysis as a theoretical realm that guides the analysis of the relationship between the subject and language in order to observe spaces provided for the mother tongue as well as translation in foreign language classrooms, aiming to pinpoint what the construction of such spaces may present concerning concepts of language, teaching and subject permeating different methodological proposals. Observing different forms of interpretation that translation may represent, this paper aims to bring contributions for teaching practice through the dialogue between these two areas.
\end{abstract}

Keywords: foreign language, mother tongue, translation, teaching/learning.

Resumo: Buscamos neste trabalho, por meio de um diálogo entre os estudos da tradução e da análise do discurso de linha pecheuxtiana, construir uma discussão sobre o lugar da língua materna e da tradução no ensino de língua estrangeira. Partimos de uma compreensão da tradução como ferramenta de auxílio na aprendizagem de uma língua estrangeira, e da análise do discurso como espaço teórico a partir do qual podemos analisar a relação do sujeito com a língua, para observarmos os espaços dedicados à língua materna e à tradução nas salas de aula de língua estrangeira, buscando apontar o que a construção desses espaços pode nos revelar acerca das concepções de língua, ensino e sujeito que permeiam diferentes propostas metodológicas. Voltando-nos para os lugares de interpretação que o trabalho de tradução pode representar, desejamos produzir contribuições para a prática de sala de aula por meio de uma interlocução entre essas duas áreas de conhecimento.

Palavras-chave: língua estrangeira, língua materna, tradução, ensinoaprendizagem. 
Este trabalho surgiu de um desejo comum de aventurar-se em outros campos e da paixão compartilhada pela língua e seu ensino. Desafiamo-nos, assim, a unir leituras que vem de campos distintos - o dos estudos da tradução e da análise de discurso de linhas pecheuxtiana -, a fim de travarmos um diálogo que nos permita pensar nos espaços que a língua materna (LM) e o trabalho de tradução tem tido no ensino de língua estrangeira (LE). Tomamos como ponto de partida duas ideias que compartilhamos: a primeira, a reafirmação da impossibilidade de silenciar a língua materna em um processo de ensino-aprendizagem de LE; a segunda, a compreensão da tradução como um espaço de interpretação que pode ser um importante auxiliar na aprendizagem de línguas.

Iniciamos este trabalho pensando no lugar que a LM ocupou e ocupa no campo das práticas de ensino de língua estrangeira LE, o que implica olhar, ainda que brevemente, para alguns momentos que marcaram mudanças nas metodologias aplicadas a esse ensino. Podemos iniciar pensando um pouco sobre as práticas de ensino-aprendizagem da língua latina, que marcavam a entrada dos aprendizes num universo de cultura. O domínio dessa língua significava a apropriação de todo um universo de produção cultural, movimento por meio do qual esse sujeito se vinculava ao mundo dos letrados. O latim, como a língua dos homens de cultura, dava aos sujeitos acesso a todo o conhecimento produzido nessa língua, conhecimento que o "ser letrado" implicava dominar. Podemos pensar, com Celada ${ }^{3}$ (2002), que essa compreensão acerca da língua latina reflete o imaginário que sobre ela se produziu, vinculando-a, dentro de uma formação social, a filiações de memória que vão determinar o lugar que essa língua ocupa em determinado universo social e, portanto, também as práticas de ensino-aprendizagem que a cercam. Entendida, a língua latina, como língua de cultura, seu aprendizado tinha, então, como objetivo, levar o aprendiz a ler textos clássicos e ter acesso ao conhecimento cultural acima mencionado.

Quando a proximidade com a língua do outro deixa de ser apenas a possibilidade de ter acesso ao patrimônio cultural nela produzido, interpondo-se nessa relação interesses de outra ordem (comercial, diplomática, etc), esse imaginário tende a se modificar, alterando-se também os lugares que dentro de uma organização social os sujeitos atribuem à(s) língua(s). Tais movimentos afetam significativamente as práticas de ensino-aprendizagem, o que se fez sentir a partir do momento em que surge a necessidade de se comunicar não apenas através da leitura, mas também da fala e da escrita em LE: os métodos de ensino de LE começam a se adaptar a novas necessidades e demandas, inaugurando outros movimentos em relação a esse ensino. O que se manteve em comum, no entanto, entre os diferentes métodos de ensino de LE foi o fato de os professores controlarem a forma da língua estudada, oferecendo aos aprendizes o modelo da estrutura desejada considerada como correta. Ou seja, o estudante aprende a repetir estruturas em uma determinada língua, mas não desenvolve a habilidade de usar a língua com mais liberdade, não combinando estruturas ou experimentando o real desenvolvimento do conhecimento da língua estrangeira.

Entretanto, apesar dessa tentativa de controle, é justamente quando começa a estabelecer comparações entre a LE e a LM que o aprendiz passa a se mover com mais liberdade nessa outra língua, já que passa a questionar estruturas e vocabulário, percebendo as distinções (e semelhanças) entre as línguas materna e estrangeira. Nesse aspecto, o aprendiz, indiretamente, está lidando com a tradução de forma didática, observando como as línguas se constroem e que particularidades apresentam (culturais, geográficas, de faixa etária etc.). O desafio ao ensino de língua estrangeira na atualidade é propor formas de

3 Em seu trabalho, Celada (2002, p. 24) discorre sobre o "modelo tetralinguístico" (Deleuze e Guattari) para analisar como as línguas estrangeiras, numa formação social dada, irão se associar a filiações de memória. 
ensino de línguas que integrem atividades que trabalhem a forma ou estrutura e o uso ou comunicação da língua estudada, sem desconsiderar a dimensão sócio-histórica que toda língua comporta. Antes de nos determos nesse ponto, entretanto, passemos a observar algumas características dos métodos de ensino de língua estrangeira.

\section{1 (Dês)encontros entre LM e LE}

Embora saibamos que são muito anteriores a ele as práticas de ensino de língua estrangeira, vamos começar essa nossa breve passagem pelas metodologias de ensino ${ }^{4}$ de LE pelo Método Tradicional (MT), que surge no século XVIII, inspirado pela prática dos exercícios de versão e gramática com textos em língua estrangeira. Visava, então, o referido método, também conhecido como Gramática e Tradução, o ensino do Latim e do Grego, e as aulas, que se centravam em exercícios de gramática e tradução, eram ministradas na língua materna do aprendiz. Ao falar sobre o método tradicional, Mascia (2003, p. 214) comenta que nele "a língua é concebida como um conjunto de regras e exceções observáveis em frases ou textos e suscetíveis de serem encontradas na língua de partida". Isso explicaria a insistência na memorização de regras, permitindo ao aluno o seu domínio e a garantia de correção e adequação no uso da língua. É preciso, no entanto, lembrar que tal ensino deveria dar ao aluno acesso à tradição cultural e literária produzida nas línguas alvo, o que faz com que se mantenha, no MT, de certo modo, concepção da existência de uma cultura a ser ensinada, aquela que se deveria cultuar e compreender, assimilar e reproduzir. Não era a língua o elemento central de interesse nesse momento, mas o que se produzia ou registrava por meio de seu uso, estando ela limitada a um papel puramente instrumental.

Em trabalho anterior (DE NARDI, 2007, p. 86), afirmamos ser possível dizer que lidamos, no MT

[...] com um certo imaginário de língua, em que o código linguístico estabelece uma ponte direta entre o sujeito que domina essa língua estrangeira, no caso o latim, e um universo de produção cultural e intelectual que foi registrado por meio dela, o que o alçava a uma posição social superior em relação ao domínio da cultura. Assim, se a língua constitui um repertório de palavras e regras cujo domínio garante ao sujeito o direito de pertencer à cultura, ela também, aqui, está presa a um certo imaginário, qual seja, o de conjunto restrito de obras que se precisa conhecer e dominar para fazer do seleto grupo daqueles que dominam o saber cultural.

Estamos diante, portanto, de uma língua que se pode dominar, apreendendo-a a partir de seus fragmentos; língua da totalidade, que se apresenta como um corpo sem fissuras. Lidamos, ainda, em relação à língua e à cultura, dentro desse imaginário, com a separação entre as margens e o centro, como se houvesse uma fronteira clara entre um núcleo ideal e aquilo que, por estar fora, não pode lhe tocar.

Embora estejamos pensando em práticas já muito antigas, o que percebemos é que resquícios desse modo de compreender a língua vão atravessar diferentes metodologias. Ao comentar a questão, Rajagopalan (2003) afirma que o conceito clássico de língua torna-se cada vez mais difícil de sustentar devido ao fato de que tal conceito abriga a ideia de auto-suficiência da língua, não observando as heterogeneidades que marcam todas as

4 Trazemos, nesse capítulo, algumas discussões sobre as metodologias desenvolvidas em De Nardi (2007), as quais, no entanto, estão sendo revistas aqui a partir do olhar do campo da tradução. 
comunidades de fala. Ou seja, os grupos dominantes vão se fortalecendo e se isolando, enquanto as diferenças são ignoradas e tratadas como fenômenos contingentes a ser estudados num segundo momento. Segundo Fairclough (1992), a língua é abordada como ela poderia ser num mundo ideal e paradisíaco e não como ela de fato é no mundo real.

No contexto de ensino de língua estrangeira esse fenômeno torna o aprendiz inseguro e receoso de cometer erros, silenciando-o em sala de aula. A consequência disso é que os esforços didáticos se voltam para a aquisição de uma competência linguística perfeita, que é um conceito suspeito relacionado ao domínio que o falante nativo supostamente possui da sua língua (cf. RAJAGOPALAN, 1997). Sem nos aprofundarmos mais na discussão acerca da noção de competência, é importante ressaltar que subjaz a esse desejo a ideia de uma comunicação sem interferências, por meio da qual é possível dizer tudo o que se quer. Por isso o aprendiz é levado a buscar se comportar como um "falante nativo", como se em nossa língua materna pudéssemos dizer tudo, dominar o seu todo. Tal postura só se sustenta, como comentamos acima, se trabalhamos no campo da língua ideal, postura perigosa seja em relação à auto-estima do aluno, que tenderá a buscar abrigo em sua língua materna, sem se aventurar na LE que aparecerá, portanto, como um lugar inacessível; seja em relação ao universo que cerca a língua algo, o qual ficará marcado como um espaço de idealizações ${ }^{5}$.

Mas voltemos um pouco ao nosso percurso histórico. As novas exigências relacionadas ao ensino de LE promovem uma mudança no cenário das metodologias, que iniciou com um questionamento acerca da eficácia do MT e a introdução de uma nova proposta metodológica que, em meados do século XX passa a ser conhecida como Método Direto (MD). Nesse modelo, que estava baseado nos processos de aquisição de LM, a proposta era o contato direto com a língua-alvo e um afastamento da língua materna do aprendiz. O lugar antes destinado à leitura e ao trabalho de tradução de textos passa a ser ocupado pela oralidade, que ganha lugar de destaque no processo de aquisição de LE. O recurso à tradução é deixado de lado e o desejo que subjaz o trabalho proposto por esse método é o de levar o aluno a pensar na língua estrangeira.

Evitar a língua materna nas interações em sala de aula e, consequentemente, todo e qualquer exercício de tradução, parecia ser um elemento essencial para a eficácia da proposta, distanciamento que trazia consigo a ilusão de que nada havia na experiência do aprendiz com a língua materna que pudesse ser proveitoso nessa situação de aprendizagem. O recurso à LM apresentava-se, portanto, como um risco, uma fonte produtora de interferências na expressão do aprendiz, a qual deveria desenvolver-se naturalmente a partir da imersão desse aprendiz na língua e a repetição do lhe era oferecido pelo professor.

Pese a mudança de perspectiva, seguimos lidando, no MD, com um conceito de língua em que ela é apresentada como apreensível em sua totalidade. Seguimos, portanto, diante "de uma língua transparente a ser dominada, pela repetição, por um sujeito que pode dizer nela o que desejar, aquilo que seu pensamento, a ser forjado nessa segunda língua, pedir que ele manifeste" (DE NARDI, 2007, p. 88). De acordo com Coracini (2005, p. 9), essa ideia de língua transparente é ilusória, pois a autora apresenta a convicção da "impossibilidade de determinar a separação entre as línguas que vão constituindo o sujeito à medida que com elas vai se identificando, se transformando na mistura da língua de outros - textos, discursos, memória, desejo... As línguas vão se "contaminando”, (es) tragando a tão desejada e impossível pureza da língua materna ...”.

5 Moita Lopes (1996) chama a atenção para essa questão ao alertar sobre o imaginário de perfeição que tal postura pode criar em relação à língua alvo e também a tudo que a ela está vinculado: os sujeitos que a tem como língua materna, os países de que são idiomas oficiais e sua cultura, etc. 
Voltamos, de certo modo, ao necessário alerta sobre o risco das idealizações de que falamos anteriormente, tema acerca do qual vale mencionar a reflexão que nos traz Rajagopalan (2003) quando afirma que em um mundo globalizado ${ }^{6}$ como o de hoje, as línguas estão sofrendo influências mútuas numa escala sem precedentes, ou seja, o português sofre influência do inglês, que sofre influência do espanhol e, assim, sucessivamente. Segundo o autor, quem ainda pensa que uma língua estrangeira é representada por seus falantes nativos, como se tais falantes fossem perfeitos e incapazes de cometer "erros" linguísticos, na verdade, ainda está vivendo no século XIX quando entes como nação, povo, indivíduo eram concebidos em termos de uma lógica binária segundo a qual só se admitia uma resposta categórica do tipo 'sim' ou 'não'.

É necessário que os aprendizes, bem como o professor de língua estrangeira, tenham em mente que línguas são espaços de interlocução e da própria expressão das identidades de quem elas se apropriam. Segundo Rajagopalan (2005), as línguas se apropriam da identidade de seus falantes, influenciando a forma como enxergamos o mundo e a nós mesmos. Ainda que estejamos imersos na ilusão de dominar a língua, o que ocorre é que somos tomados por ela. Quem transita entre diversos idiomas está redefinindo sua própria identidade. Quem aprende uma língua nova está se redefinindo como uma nova pessoa. O destronamento da figura do falante nativo faz pensar em metas mais razoáveis e executáveis no ensino de LE. O verdadeiro propósito do ensino de LE é formar indivíduos capazes de interagir com pessoas de outras culturas e modos de pensar e agir. Significa se transformar em um sujeito capaz de lidar com as diferenças (sem que isso implique mergulhar na ilusão de poder dominar esses espaços) existentes entre as línguas e entre os povos, sabendo distinguir e perceber a importância de sua língua materna em contexto de aprendizado de língua estrangeira. Isso implica, para o professor de língua, a necessidade de compreender, também os momentos em que é preciso focar na língua estrangeira para que o aluno desenvolva o conhecimento necessário nessa LE.

Não se trata, portanto, de substituir a LE em sala de aula pelo uso da LM, o que pretendemos mostrar, apenas, é que seguir insistindo na ideia da possibilidade de isolar o sujeito de sua língua materna implica mergulhar na ilusão da separação entre sujeito e língua, ignorando o papel da língua na constituição das identidades. Entendemos ser impossível fazer o sujeito retornar a um estágio de desconhecimento de sua língua materna para supor a possibilidade de que ele venha a inserir-se totalmente despido de suas influências no universo de uma LE, já que, como nos mostrou Revuz (1998), entrar em contato com uma segunda língua provoca deslocamentos nas construções identitárias do sujeito, modificando também a sua relação com a língua materna.

Ao olharmos para a língua enquanto materialidade do discurso, conforme nos ensina Pêcheux (1997), temos a possibilidade de ressignificar a relação entre sujeito e língua, que não é nunca de completo domínio e controle, como também comenta Rajagopalan (1997; 2003), que citamos anteriormente, mas de encontro. A língua se inscreve nos sujeitos, em seu corpo, e é impossível, portanto, no caso da língua materna, apagar suas marcas nesse sujeito, fazendo com que dela se "esqueça" ainda que temporariamente. Para Gadet e Pêcheux (2004, p. 45), é "por amor à língua que alguém se torna "louco pela língua"; por amor e inicialmente pelo apego primeiro ao corpo da mãe, quando sua insistência toma a forma de um amor da língua-mãe ou da língua materna”. A relação do sujeito com a

6 Não nos ocuparemos aqui da discussão acerca do processo de globalização e das diferentes formas pelas quais podemos enxerga-lo; referimo-nos, apenas, à reflexão de Rajagopalan para reforçar que, a partir de diferentes lugares teóricos, é possível afirmarmos a impossibilidade de negar à língua e aos sujeitos sua heterogeneidade. 


\section{Conexão Letras}

língua materna está intrinsecamente ligada à sua constituição como tal ${ }^{7}$, e, portanto, à sua identidade, que se constrói por meio dessa materialidade.

Afastamo-nos a partir de nossas reflexões, da preocupação, por vezes obsessiva, em isolar o aprendiz de LE de sua língua materna, que se fez presente em práticas inspiradas, por exemplo, pelos Métodos áudio-oral e audiovisual que ganharam força entre os anos 40 e 50 do século XX. Defendia-se, então, que o domínio da LE deveria se dar pelo seu uso exclusivo, sem interferências da língua materna do aprendiz. Dominavam essas propostas os exercícios de repetição e a memorização das estruturas, por meio das quais se visava conquistar o domínio da língua-alvo. Em meados dos anos 50 surge, ainda, o Método audiovisual, que tinha como princípio substituir, pelo recurso à imagem, a necessidade de se buscar na língua materna do estudante as explicações acerca dos elementos estudados na língua estrangeira. Esse movimento, entendemos, promove um retorno a uma concepção de língua enquanto repertório de palavras, cada uma correspondendo a um referente no mundo exterior que ela designa.

É importante notar que o movimento de silenciamento da língua materna a que nos opomos, embora minimizado, ainda está presente nos LDs para o ensino de língua espanhola e de língua inglesa no Brasil. Esses materiais, que em sua maioria seguem a orientação comunicativa, não preconizam abertamente a exclusão da LM da sala de aula de LE, mas percebe-se uma forte tendência a orientar o professor a não recorrer ao uso da língua materna ou da tradução e fazer uso de imagens como forma de substituir as comparações com a LM.

Por volta dos anos 70 do século XX inicia-se um movimento de reação aos métodos áudio-oral e audiovisual que vai se configurar no que costumamos designar de Abordagem comunicativa. Dois princípios chamam a atenção em relação a essa abordagem: a ausência de uma preocupação em afastar o aprendiz de LE da língua materna e a integração do erro como parte natural do processo de ensino-aprendizagem. A língua é vista pelos seguidores dessa abordagem como um instrumento de comunicação ou de interação social, e o objetivo do trabalho a ser desenvolvido é a conquista da competência comunicativa do aprendiz; compreende-se, portanto, que além de ler e escrever orações nessa língua, o estudante deve conhecer as maneiras como ditas orações são utilizadas para se conseguir um determinado efeito comunicativo. O olhar dos comunicativistas, ao tomar a noção de competência, estava voltado para a observação das capacidades dos indivíduos como membros de uma comunidade linguística, o que os fez afirmar a insuficiência da competência linguística e aproximar-se de uma concepção cognitivista de aprendizagem.

Sem negarmos os importantes avanços que trouxe a abordagem comunicativa, compartilhamos, no entanto, com Mascia (2002), a preocupação que expressa ao analisar os pressupostos da referida abordagem, quando alerta para o fato de que ao vincular a aprendizagem de uma língua à capacidade de aprender a formar regras que levassem à construção de novos enunciados, a abordagem comunicativa tende a delegar ao pensamento um papel de relevância "na descoberta de regras de formação de enunciados", o que pode implicar em um predomínio do pensamento sobre a expressão, que é dominada por ele, tendo como possível consequência a colocação da língua numa posição meramente instrumental e do sujeito como aquele que é capaz de apropriar-se desse instrumento para expressar tudo aquilo que o seu pensamento criou. Sem nos alongarmos mais nessas discussões, que embora importantes não são o centro de nossa reflexão, cabe lembrar o que

7 Retomamos aqui uma postura que temos defendido em outros trabalhos, a exemplo de De Nardi (2007) e De Nardi e Grigoletto (2011), postura que nos une ao modo como Branco (2009) tem trabalhado a questão da tradução. 
comenta Coracini (1997) acerca da abordagem comunicativa e sua chegada ao Brasil na década de 80 . Segundo a autora, teoricamente sua inserção implicaria num deslocamento do foco do trabalho com LE "do ensino para a aprendizagem", fazendo, por exemplo, com que, embora ainda se preconize o uso da língua estrangeira em sala de aula, tenha se tornado consensual o recurso à tradução/ comparação com a língua materna quando isso se apresentar como um facilitador do trabalho com a LE em sala de aula. Para Coracini (1997, p.156), no entanto, a aprendizagem passa a ser vista como um processo idealizado e homogeneizante, estabelecendo-se uma diferença importante entre a aquisição da língua materna, processo inconsciente, e a aprendizagem de uma língua estrangeira, tido como um processo completamente conscientemente e controlável. A preocupação da autora é com o fato de que tal postura acaba por aumentar a distância entre uma língua e outra, colocando a LE sempre como algo exterior ao indivíduo.

O que entendemos é que insistir na compreensão do processo de ensino-aprendizagem como algo predominantemente consciente e controlável é ignorar, também, as contribuições que a psicanálise tem dado a esse campo e que nos mostram que as resistências à língua do outro, e muitas vezes à nossa própria língua, podem vir de outro lugar que não das deficiências de aprendizagem ou da recusa consciente de apreender esse conhecimento ${ }^{8}$. Esse domínio do sujeito, seja da língua, seja de seu processo de ensino-aprendizagem, é avesso à noção de um sujeito descentrado, como é o sujeito da $\mathrm{AD}$, que não domina totalmente nem a língua nem as condições de produção do dizer.

Nesse sentido, vale lembrar o que nos diz Coste (2002, p. 11), acerca da noção de competência. Para ele, importa lembrar que em sua apropriação pela didática de línguas esse conceito sofreu o que designa de deslizes interpretativos, quais sejam: (a) falar-se em competência comunicativa restringindo-a à capacidade de trocas orais eficientes, limitando a amplitude do conceito aos diálogos; (b) considerar-se a competência comunicativa como uma totalidade única, supondo, a exemplo de Chomsky, que todos os falantes de uma língua têm a mesma competência; (c) produzir-se uma dicotomia entre competência linguística e competência comunicativa. O que propõe o autor é que busquemos a aplicabilidade do conceito de competência comunicativa a reflexões sobre os processos de leitura em língua estrangeira, afastando-nos da consideração de que a aquisição de uma sintaxe e de um vocabulário possa ser tomada como o objetivo do processo de ensino de uma língua estrangeira.

Entendemos ser possível recorrer, nesse caso, à visão de Nord (1997) sobre a tradução como comunicação, seguindo um propósito para que aconteça. Mesmo em sala de aula, a tradução, como vista na atualidade, deve ser utilizada com um propósito semelhante ao do Método Comunicativo de ensino de língua inglesa. Ou seja, a tradução, segundo a autora, promove cooperação intercultural além de ato comunicativo que não seria possível devido a barreiras linguísticas e culturais. A tradução pode entrar em ação na prática em sala de aula de línguas estrangeiras para facilitar o entendimento intercultural, oferecendo alternativas para questões linguísticas muitas vezes não possíveis de serem abordadas caso a língua materna seja deixada de lado ou sem usar ferramentas tradutórias em atividades específicas. Sem fazer o papel de ponte ou de espaço de transmissão de uma informação ${ }^{9}$, seja ela linguística ou cultural; o que acreditamos que o exercício da tradução

8 Em De Nardi (2007) trabalhamos de forma mais detalhada com essa questão ao retomar discussões de AMATI-MEHLER, J.; ARGENTIERI, S.; CANESTRI, J. A Babel do Inconsciente: língua materna e línguas estrangeiras na dimensão psicanalítica. Rio de Janeiro: Imago, 2005.

9 Não poderemos nos ocupar, nesse texto, de uma discussão mais aprofundada sobre as diferentes concepções de tradução, mas gostaríamos de remeter, nesse momento, aos trabalhos de Mittmann (2003) e Coracini (2005) em que tais discussões aparecem, marcando posições às quais nos aliamos nesse trabalho. 


\section{Conexão Letras}

possa trazer para a sala de aula é um espaço de produção de sentidos em que sua voz irá aparecer trazendo as marcas do lugar que ocupa nessa relação entre línguas. Traduzir não é, portanto, reproduzir com fidelidade, em nosso caso, em sua língua materna os sentidos que do texto original deveriam emergir, mas produzir um novo texto nessa outra língua que também está inserido em condições de produção específicas.

Enfim, para encerrar essa nossa passagem pelo lugar de LM e LE em diferentes metodologias de ensino, o que fizemos a fim de marcar o nosso lugar nesse caminho de (des) encontros, pensamos ser possível afirmar que os resquícios de uma insistência histórica no efeito nocivo do recurso à língua materna no processo de ensino-aprendizagem de segunda língua ainda podem ser vistos em aulas de LE e no material didático produzido para esse ensino. Ao analisar as metodologias de ensino de língua estrangeira, o que nos chama a atenção é que, pese os avanços que alguns métodos conseguiram trazer, a concepção de língua tende a se manter inalterada, havendo uma tendência a que se trate a língua como um código a ser apreendido para que com ele possamos expressar o pensamento, o que coloca o sujeito na posição de quem é capaz de dominar a língua e utilizá-la a serviço de sua expressão.

Dedicaremos o próximo subtítulo a tentar delimitar como estamos compreendendo o trabalho de tradução e sua inserção nas práticas de ensino de LE.

\section{Olhares sobre a tradução e o ensino}

Sem a pretensão de que esse trabalho seja uma revisão acerca das diferentes orientações dos estudos de tradução, o que vamos buscar, nesse momento, é apontar como estamos entendendo o trabalho de tradução, pensando especificamente em seu lugar nas práticas de ensino-aprendizagem de LE. Como adiantamos anteriormente, o que se observa é que por muito tempo vivemos a ilusão da possibilidade de uma tradução termo a termo de uma língua para a outra, e nesse sentido, o exercício constante da tradução na aula de LE levava, não raro, a se desconsiderar o fato de que, diante de uma outra língua, estamos em face de uma nova estrutura, com tudo o que ela pode abrir, e, portanto, com movimentos próprios de produção de sentido. De certo modo, o exercício da tradução via-se afetado pela crença de que é possível dizer tudo na língua, na nossa e na do outro, e que há sempre uma possibilidade de correspondência direta entre as línguas, vistas apenas como suporte para a expressão de algo que lhe é anterior.

Quando nos afastamos de uma noção de língua transparente, de um sujeito intencional e, portanto, do texto enquanto depositário de um sentido original - que caberia ao leitor/tradutor/aprendiz decodificar -, podemos caminhar em direção a um lugar em que as reflexões sobre os propósitos do ensino de língua estrangeira e as reflexões sobre a tradução se aproximam. Cabe destacar, em relação a isso, a consideração de que o sentido se produz pelo entrecruzamento de elementos linguísticos e de uma exterioridade que é constitutiva do discurso, e, portanto, está na língua. Elementos que designamos como situação, tema e códigos sócio-culturais, entre outros, passam a ser matéria desse trabalho com a língua e seu ensino-aprendizagem, podendo o exercício da tradução colaborar fortemente para que o sujeito-aprendiz experimente esse movimento de deslocar-se entre diferentes lugares, colocando-se como leitor nesses espaços de discurso.

Língua materna e a língua estrangeira se interpenetram na constituição da subjetividade. Falando especificamente do tradutor profissional, é possível descrevê-lo como um sujeito entre línguas, culturas, onde línguas/culturas se mesclam, se misturam, se confundem; onde se apagam ou se embaraçam os limites, os contornos e as dicotomias. 
O professor de língua estrangeira no Brasil parece estar em contexto bem próximo daquele do tradutor profissional, pois, ao mesmo tempo em que permanece em situação de língua materna, precisa ensinar a língua e cultura do Outro, causando, também, mescla e confusão, no que podem essas palavras ter de desafiadoras e produtivas.

Estamos entendendo, portanto, a tradução, nesse trabalho, em seu sentido amplo, como um exercício de interpretação, que implica para o sujeito que se coloca na condição de aprendiz de uma língua estrangeira a possibilidade de produzir sentidos a partir do que lê nessa outra língua, seja para falar na língua do outro seja para recolocar esse saber em seu universo, em sua língua materna. Em seu trabalho sobre as notas do tradutor, Mittmann (2003, p. 42), ao fazer reflexões que tomamos como base para muitas das considerações que aqui fazemos sobre o lugar da tradução na sala de aula de LE, define o que chama de processo tradutório como "o processo de produção de um discurso que se materializa no texto da tradução, e que tem como especificidade partir da leitura de um texto específico anterior, o texto original". Como nos ajuda a compreender a autora, pela tradução não transportamos significados, mas produzimos discursos que estarão também expostos à interpretação.

Além disso, ao analisarmos mais especificamente o lugar da tradução nesse processo de ensino-aprendizagem e o modo como ela tem sido tratada, ao pedir ao estudante ou ao professor para não traduzir ou usar a língua materna em sala de aula, é ignorado o fato de que a tradução não acontece única e exclusivamente de forma verbal (escrita e/ou falada), mas também de forma não verbal, como já descreve Jakobson (1958) em suas categorias de tradução, presentes no texto do autor reproduzido em Venuti (2000):

1. Intralingual: interpretação de signos verbais através de outros signos da mesma língua.

2. Interlingual: interpretação de signos verbais através de outra língua.

3. Intersemiótica: tradução ou transmutação - interpretação de signos verbais através de sistemas de signos não-verbais (VENUTI, 2000, p. 114).

Como pode ser observado, Jakobson vai além da tradução de textos verbais de uma língua para outra, sugerindo que a tradução acontece dentro da mesma língua, com uso de paráfrase ou circunlocução, por exemplo. A utilização de filmes, expressões faciais e imagens em geral são possibilidades de tradução intersemiótica. Já a tradução entre línguas pode ocorrer em situações específicas, sem causar prejuízo ao desenvolvimento do trabalho de sala de aula, desde que bem preparada e com objetivos claros, tanto para o professor quanto para o aluno. Qualquer uma das categorias de tradução acima descritas pode ser utilizada em contexto de ensino de língua estrangeira, favorecendo o aprendizado de línguas.

Assim, podemos reforçar a ideia de Jakobson sobre o fato de que a função cognitiva da língua não depende apenas de padrões gramaticais, mas de operações metalinguísticas que seguem lado a lado com questões tradutórias. Pensando nesses aspectos, podemos ver o ambiente de sala de aula de línguas estrangeiras por outro ângulo mais abrangente e não tentar reprimir o aluno em sua forma de pensar e trabalhar as línguas envolvidas no processo. Ao ordenar ao aluno que "não use a língua materna em ambiente de língua estrangeira", estamos exigindo algo impossível, uma vez que é na língua materna que o aluno tem a construção de suas ideias estabelecidas e, a partir dela, vai formando seu conhecimento e utilização da língua estrangeira estudada. Isso acontece pelo fato de que "o nível cognitivo da língua não apenas admite, mas exige a interpretação decodificada, 


\section{Conexão Letras}

isto é, a tradução ${ }^{10 "}$ (JAKOBSON, 1958/2000, p. 116) de ideias, frases, palavras, da forma de pensar e agir de uma determinada comunidade (BRANCO, 2009).

Olhares diferentes, de tempos distintos, embora guardem divergências entre si, parecem nos mostrar que ao ampliar a noção de tradução é possível trazê-la de maneira produtiva para o espaço da sala de aula de línguas, especialmente se ao aproveitarmo-nos da impossibilidade de traduzir termo a termo um texto de uma língua para outra, pudermos desafiar o aluno a reconhecer essa ilusão do todo que vivemos em nossa própria língua. Como comenta Mittmann (2003, p.61), ao falar sobre "a ilusão da relação direta entre a coisa e a palavra", "o próprio processo tradutório, muitas vezes, encarrega-se de desfazer esta ilusão, quando o tradutor se depara com a inadequação entre as línguas, com os diferentes recortes de real que cada língua efetua".

Além disso, no contexto de ensino de língua estrangeira, Hurtado Albir (1998, 42) afirma que "tradução é um processo de reexpressão do sentido que as palavras e frases adquirem no contexto". Ou seja, utilizada pelo professor em sala de aula, com objetivo didático. É importante frisar que não temos o objetivo, aqui, de fazer da aula de LE um exercício constante de tradução, mas pensar que também há um espaço importante para essa prática, observando os desafios que ela implica, sempre levando em consideração o contexto linguístico e situacional, nunca traduzindo palavras ou frases isoladas, com objetivo didático. Conforme afirma Pegenaute (1996), o professor deve apresentar o processo tradutório aos alunos seguindo um processo interpretativo que compreende diversas fases, todas elas com suas características particulares e os desafios que compreendem.

Por fim, gostaríamos de destacar que entendemos ser o recurso à tradução em sala de aula um importante momento de troca de papeis sociais em sala de aula por parte de professor e aluno, pois ao propor-se a discutir com o aluno as traduções possíveis para o que lhe é apresentado como texto de partida, constrói-se a possibilidade de um equilíbrio de poder em sala: o aluno recupera a voz silenciada. Exercícios que envolvam tradução podem contribuir para um maior envolvimento do aprendiz no processo de aprendizagem da língua estrangeira, uma vez que lhe é dado o direito de (re)escrever o que encontra como produção nessa outra língua, colocando-se diante desses dizeres enquanto sujeito-leitorprodutor de discursos. Experimentar-se como tradutor pode ser um modo, portanto, de olhar para as suas próprias resistências na língua do outro, e aqui nos permitimos um jogo com o termo resistência que Mittmann (2003, p. 63) usou para definir o caráter do processo tradutório, que segundo ela, longe de tornar o trabalho de tradução impossível, "revela que há diferenças e semelhanças, distância e proximidades, equívocos, deslizamentos, falta e excesso, tanto entre as línguas como dentro de cada língua”.

Como resultados mais imediatos, o trabalho com a tradução em sala de aula tem demonstrado que ele é capaz de propiciar ao aluno a ampliação do léxico, de que precisa se ocupar com detalhes, além de uma melhora na audição e expressão oral na LE, mas tende a desenvolver, especialmente, uma visão mais ampliada e crítica da cultura produzida na língua estrangeira, além de desafiá-lo a traduzir sua própria cultura.

Aqui, parece interessante, citar um exemplo de atividade de tradução que envolve as quatro habilidades (escuta, fala, leitura e escrita) em contexto de sala de aula de língua inglesa como língua estrangeira.

10 the cognitive level of language not only admits but directly requires recoding interpretation, i.e., translation (apud VENUTI, 2000, p. 116). 


\subsection{Chapeuzinho vermelho em tradução}

A atividade foi desenvolvida em uma disciplina do Curso de Letras - Inglês da UFCG e envolveu questões linguísticas e literárias. A atividade foi sendo desenvolvida durante o semestre, tendo início com a descrição de como o conto de fadas é trabalhado em contextos culturais diversos, em países diferentes. Foi abordado como esse gênero vai sendo adaptado para a cultura alvo, observando o propósito de leitura no novo contexto. Antes da leitura do conto, os estudantes leram a respeito dos autores e de como a narrativa foi construída dentro do contexto francês e alemão, respectivamente, de Charles Perrault (1628-1703) e dos Irmãos Grimm (1785-1863). A partir das leituras, foi feita a discussão sobre como o conto Chapeuzinho Vermelho foi sendo transformado para o contexto brasileiro.

Foram analisadas questões que envolveram teorias mais voltadas à literatura. Entretanto, como o foco do trabalho era linguístico, foram abordados pontos sobre estratégias de tradução e o uso de abordagens linguísticas variadas. Após as discussões e o trabalho teórico, foi solicitado que os estudantes, em pequenos grupos, produzissem uma adaptação do conto Chapeuzinho Vermelho para o contexto do nordeste do Brasil, sugeridose que eles utilizassem qualquer uma das culturas específicas do nordeste brasileiro como cenário. Foi também pedido que os estudantes apresentassem um prefácio explicando: i) o contexto e escolhas para a adaptação; ii) escolhas de linguagem e quaisquer outros detalhes considerados relevantes; além iii) da referência bibliográfica de suas pesquisas sobre os autores e contos. Sugeriu-se, ainda, que eles utilizassem ilustrações e recursos tradutórios, como notas de rodapé, por exemplo.

Com esse tipo de trabalho, é possível observar o uso das categorias de tradução de Jakobson, bem como a Abordagem Funcionalista de Nord (1997) nas explicações fornecidas através de notas de rodapé, ilustrações e de adaptações feitas, levando em conta questões sociolinguísticas e culturais. O resultado final foi bastante interessante, tendo um dos grupos situado o conto na cidade de Patos, no interior da Paraíba, e todo o contexto foi adaptado para tal localidade, inclusive com linguagem típica da região - 'fulô', para 'flor' e 'vrimei' para 'vermelho', por exemplo. O lobo, por sua vez, era um touro. Outro grupo localizou o conto na cidade de Campina Grande, também no interior da Paraíba, no período junino: o lobo mau foi representado por um forrozeiro que tenta violentar Chapeuzinho e a moral da história foi não confiar em estranhos. Os textos foram ilustrados, comentados e houve inclusão de paratextos, como notas de rodapé ${ }^{11}$ e os prefácios.

As apresentações das produções foram feitas em língua inglesa, fazendo com que os estudantes se expressassem na língua estrangeira estudada, buscando explicar suas opções tradutórias, ao mesmo tempo recorrendo à língua materna, quando necessário, para comentar contextos específicos, recorrendo, também, às imagens utilizadas. Ou seja, todos os estudantes participaram com comentários, questionamentos, sugestões, sendo ouvidos e utilizando tradução em contexto de ensino de língua estrangeira, o que nos mostra que a tradução pode acontecer promovendo o uso da língua estrangeira, favorecendo um ambiente que promova a comunicação mais fluente por parte dos estudantes.

$\mathrm{O}$ que atividades como a que acima descrevemos brevemente têm nos mostrado, portanto, é que o exercício da tradução pode, como afirmamos anteriormente, constituirse em um importante espaço de inserção da voz do aprendiz no processo de ensino-

11 É interessante observar, como nos mostra Mittmann (2003), o papel exercido pelas notas de rodapé no trabalho de tradução (e, poderíamos nos arriscar a dizer), também naquele de produtores de texto, constituindo-se um espaço em que se revela tanto a tentativa de controle da deriva dos sentidos, quanto o de manifestação de um desejo de responsabilidade compartilhada sobre o dizer. 
aprendizagem de LE, uma vez que, desobrigado a responder com "fidelidade" aos sentidos que supostamente deveria reproduzir a partir do texto fonte, lhe é propiciada a possibilidade de assumir um lugar de autoria na (re)construção desse dizer, que passa a ter as suas marcas e aquelas do espaço social em que está inserido. Além disso, vale lembrar o que o nos diz Pegenaute (1996), para quem a tradução apresenta possibilidades didáticas que: i) ensinam a traduzir; ii) ajudam no aperfeiçoamento das línguas estrangeira e materna; iii) auxiliam na formação intelectual e iv) ajudam na melhora da leitura. Os aprendizes passam a ser mais ativos e participativos, pois se tornam mais questionadores e buscam explicações para as comparações entre línguas e situações em sala de aula, como demonstrado na atividade de tradução utilizando um conto de fadas acima. Em outras palavras, mesmo em contexto de sala de aula de línguas estrangeiras, o trabalho de tradução está presente.

Embora não nos tenhamos detido nessa questão, o anteriormente exposto nos leva a reafirmar a necessidade de considerarmos a historicidade da língua como forma de ressignificar a imagem acerca da tradução, ainda muito pautada pela crença da possibilidade de uma tradução palavra por palavra, como se houvesse sempre uma correspondência direta na LM para aquilo que se diz na língua do outro. Tal correspondência, entretanto, inexiste, pelo fato de que as línguas possuem estruturas particulares, bem como formas diversas de se historicizar, fazendo com que qualquer trabalho de tradução que aconteça em sala de aula leve em conta contextos e momentos específicos, bem como o ambiente linguístico-cultural dessa língua, independentemente da língua materna dos aprendizes. Pensar a tradução no contexto atual do ensino de línguas é levar em conta não apenas regras e estruturas, mas também o sujeito como parte importante do processo, considerando-se tanto as condições de produção a que responde aquele de traduz o texto, quando o lugar ocupado pelo sujeito que usufruirá da tradução, levando-se em conta o contexto em que ela se enquadra.

\section{Considerações finais}

Nossas considerações finais nesse trabalho são realmente a tentativa de fazer laço no dizer, constituindo-se, para nós, não num ponto final, mas no passo primeiro de um diálogo que, entendemos, ainda possa render outros frutos. Por isso, vamos insistir aqui nos pontos que nos unem e que gostaríamos que ressoassem sobre o modo como entendemos que a tradução possa ser convocada a fazer parte das práticas de sala de aula de LE. Para começar, desejamos lembrar que entendemos como infrutífera a permanência, no campo do ensino-aprendizagem de LE, de velhas práticas que se pautem pela insistência na memorização de regras, por meio das quais viria, supostamente, o aluno ter a garantia de correção e adequação no uso da língua (seja ela materna ou estrangeira). Do mesmo modo, é importante que nos afastemos da ilusão de que é possível dominar uma língua em sua totalidade e, portanto, que a mesma seja um corpo homogêneo que, no caso da língua estrangeira, está sob o domínio do falante nativo. Longe de impulsionar o aluno a aventurarse nesse novo espaço que a LE representa, a busca por uma competência linguística perfeita tendo a silenciar o aluno em sala de aula, ou por colocar a LE em um lugar inacessível; ou por marcar o espaço social de que ela é parte como um espaço de idealizações.

Isso não significa, de forma alguma, negar a importância do uso da LE nas aulas a ela dedicadas, o que seria incoerente com o desejo de conhecer os discursos de que essa língua é materialidade, mas reconhecer que há muito da experiência do aprendiz com a sua língua materna que pode ser produtivo nessa situação de aprendizagem. Além disso, longe de ser apenas uma fonte produtora de interferências na expressão do aprendiz, 
como costumavam defender os que viam o recurso a ela como um risco desnecessário, a reflexão sobre a LM na sala de aula de LE pode ser um espaço importante de descobertas sobre os (des)encontros entre essas línguas. Como procuramos defender nesse trabalho, é impossível produzirmos para o sujeito o retorno a um estágio de desconhecimento de sua língua materna, supondo que em algum momento possa livrar-se de suas influências, já que é a LM a matéria primeira de sua constituição identitária.

E se como diz Coracini (2005, p. 12), "a identidade é interpretação de si - pelos outros e por si - e do outro - por si e pelo outro -, e como traduzir é interpretar", é possível compreendermos que há um importante lugar para a tradução na sala de aula de LE. É por isso que fomos buscar em diferentes autores dizeres que nos pudessem mostrar a amplitude que pode e deve tomar a compreensão do trabalho de tradução, que não pode ser atrelado à reprodução de um texto original, mas que se constitui num importante espaço de leitura do texto e de suas condições de produção, espaço a partir do qual o sujeito pode se lançar a um trabalho de autoria que o coloque nesse espaço tenso e produtivo do estar entre línguas (e porque não dizer, entre diferentes espaços teóricos), de situar-se como alguém que joga nas línguas a partir do seu próprio lugar de sujeito, mas experimentando a tarefa de compreender o que nos diz o outro e fazer-se compreender pelo que pode dizer sobre o que nessa língua estrangeira foi produzido.

\section{Referências}

ALBIR, Hurtado. La traducción en la enseñanza comunicativa. In: Cable: Revista de Didáctica del Español como Lengua Extranjera. Madrid, 1998, p. 42-45. BRANCO, S. O. Teorias da tradução e o ensino de língua estrangeira. In: Horizontes de Linguística Aplicada. Brasília: UnB, v. 8, n. 2, 2009, p. 185-199. CELADA, M. T. O espanhol para o brasileiro: uma língua singularmente estrangeira. Campinas, SP: [s.n.], 2002. (Tese de doutorado) CORACINI, M. J. R. F. Língua estrangeira e língua materna: uma questão de sujeito e identidade. Letras \& Letras, Uberlândia, 14 (1), jul/dez. 1997.

. O Sujeito Tradutor entre a "Sua" Língua e a Língua do Outro. In: Cadernos de Tradução. Florianópolis: UFSC, v. 2, n. 16, 2005. COSTE, D. Leitura e competência comunicativa. In. GALVES, C.; ORLANDI, E.; OTONI, P. O texto: leitura e escrita. Campinas: Pontes, 2002, p.11-30. DE NARDI, F. S. Um olhar discursivo sobre língua, cultura e identidade. Reflexões sobre o livro didático para o ensino de espanhol como língua estrangeira. Tese de Doutoramento. Programa de Pós-Graduação em Letras da Universidade Federal do Rio Grande do Sul, dez. de 2007.

DE NARDI, F. S.; GRIGOLETTO, E. Entre o desejo da unicidade e o real da língua: o imaginário sobre línguas no processo de ensino-aprendizagem. In. SCHONS, C.; CAZARIN, E. A. (Org.). Língua, escola e mídia. En(ter)laçando teorias, conceitos e metodologias. Passo Fundo, RS: Editora da UPF, 2011, p. 119-144.

FAIRCLOUGH, Norman. Discourse and Social Change. London: Polity Press, 1992. GADET, F.; PÊCHEUX, M. A Língua Inatingível. Campinas: Pontes, 2004. JAKOBSON, Roman. On linguistic aspects of translation. In: VENUTI, Lawrence (Ed.). The translation studies reader. London: Routledge, 2000. p. 113-118. MASCIA, M. A. A. Investigações discursivas na pós-modernidade. Campinas: Mercado de Letras; São Paulo: Fapesp, 2002. 


\section{Conexão Letras}

Discursos fundadores das metodologias e abordagens de ensino de língua estrangeira. In. CORACINI, M. J.; BERTOLDO, E. S. O desejo da teoria e a contingência da prática. Campinas, SP: Mercado de Letras, 2003.

MITTMANN, S. Notas do tradutor e o processo tradutório. Porto Alegre: Editora da UFRGS, 2003.

MOITA LOPES, L. P. da. "Yes, nós temos bananas ou Paraíba não é Chicago não". Um estudo sobre a alienação e o estudo do inglês no Brasil. In. Oficina

de lingüística aplicada. Campinas: Mercado de Letras, 1996. (Coleção Letramento, Educação e Sociedade), p. 37-62.

NORD, Christiane. Translating as a Purposeful Activity: Functionalist Approaches Explained. Manchester: St. Jerome, 1997.

PÊCHEUX, M. Semântica e Discurso: uma crítica à afirmação do óbvio. 3. ed. Campinas: UNICAMP, 1997.

PEGENAUTE, L. La traducción como herramienta didáctica. In: Contextos, n. 2728, Madrid, p. 107-126, 1996.

RAJAGOPALAN, Kanavillil. Por uma Línguística Crítica: linguagem, identidade e a questão ética. São Paulo: Parábola Editorial, 2003.

REVUZ, C. A língua estrangeira entre o desejo de um outro lugar e o risco do exílio. In: SIGNORINI, I. (Org.) Lingua(gem) e identidade: elementos para uma

discussão no campo aplicado. Campinas: Mercado das Letras, 1998. p. 213-230.

VENUTI, Lawrence. The translation studies reader. London/New York: Routledge, 2000. 